\title{
ENGINEERING JOURTIRL
}

Article

\section{Effect of Fold-Forging Techniques for Sword Making Process on Mechanical Properties of Medium Carbon Steel}

\section{Kotchapond Paveebunvipak ${ }^{*}$, Kittipong Yu-on, Teerasak Rotpaisarnkit, Janwat Sakavaratikul, and Vitoon Uthaisangsuk}

King Mongkut's University of Technology Thonburi, Faculty of Engineering 126 Pracha Uthit Road, Bang Mod, Thung Khru, Bangkok 10140, Thailand

*Corresponding Author: jing1524@hotmail.com

\begin{abstract}
The most important procedure for making a traditional Samurai sword consists of metal forming at high temperature and subsequent quenching. Hereby, two specific techniques are additionally included, namely, fold-forging and mixing of different steel grades. In this work, both particular processes were applied to the steel grade AISI 1055, a conventional low carbon steel and the Nam-Phee steel, which has been commonly used to produce the well-known Nam-Phee sword for a long time in Thailand. Afterwards, mechanical properties of produced samples were investigated and compared. Four combinations between the examined steels and both techniques were taken into account. It was found that Nam-Phee steel samples subjected to the fold-forging obviously showed more homogenous and finer microstructure. Their resulting tensile strength, flexural strength and impact energy were significantly increased. The improved mechanical properties of the Nam-Phee specimens were close to those of the Tamahagane steel used for making Samurai sword. Moreover, AISI 1055 steel specimens mixed with the low carbon ductile steel as core exhibited much higher flexural strength and impact energy.
\end{abstract}

Keywords: Sword making, fold-forging, steel mixing technique, Nam-Phee steel, mechanical properties.

ENGINEERING JOURNAL Volume 21 Issue 4

Received 11 October 2016

Accepted 17 January 2017

Published 31 July 2017

Online at http://www.engj.org/

DOI:10.4186/ej.2017.21.4.229 


\section{Introduction}

Sword has been used as weapons for more than 3000 years in the human history. In ancient times, swords were primarily made from stone or animal bone. After that, metals such as copper, tin, lead and steel were discovered and developed to make swords. In Thailand, swords like Nam-Phee sword were collected as valuable treasure. Thai people believe that this Nam-Phee sword is a talisman, which can protect them from any danger. Nam-Phee steel was first discovered from nature ore in the Nam-Phee village, Uttaradit province, Thailand [1]. Since then the steel has been used to produce Nam-Phee sword until today. The Nam-Phee sword has shown large significance in the history. Today the traditional Nam-Phee steel extracted from Uttaradit province certainly involves spirit and folk wisdom. In other parts of the world, swords have been differently made, in which other various types of material such as Tatara steel [2-5], Tamahakana steel [6], Damascus steel [7] were used. According to documentations and archeological researches, many traditional ways for producing swords have been available, for example Japanese Samurai technique [2-6], Eastern Damascus technique, Welded Damascus technique [8-10], etc. It was reported that Japanese swords have a long history more than a thousand years, in which Japanese sword smiths have their own special techniques to produce the swords [11-14]. Currently, such Samurai swords are no longer intended to use as a weapon in Japan. However, its quality and design are so attractive for antiquary in Japan society [14]. In terms of scientific view, microstructures and mechanical properties of the Japanese swords were extensively studied by means of different characterization methods in [15-18]. However, even the Nam-Phee sword is well-established in Thailand a few investigations on its material and processing have been carried out. In recent years, microstructure characteristics and mechanical properties of the Nam-Phee steel were studied during sword fabrication [1]. Therefore, in this work, it was aimed to investigate and enhance mechanical properties of the Nam-Phee steel by applying the Samurai sword making technique including fold-forging and steel grade mixing. During the fold-forging process, steel specimen is heated, halved and forged into a desired semifinished shape at high temperature. To achieve uniform temperature distribution of specimens in a reheating furnace several factors were investigated in [19]. The steel mixing process aims to combine two steel grades with varying ductilities into one sword. High carbon steel is basically used for the outer skin, whereas low carbon steel for the inner core of the sword. It was presented that both techniques could significantly lead to increased strength and ductility of the examined Japanese swords [18, 20-21]. Afterwards, microstructure, tensile properties, bending and impact behavior of investigated steels were characterized and compared.

\section{Material and Testing Methods}

\subsection{Materials}

The Nam-Phee steel, steel grades AISI 1055 and AISI 1010 were used in this work. The steel grade 1055 was produced by Tetsusho Ueko Company, which was a hot rolled plate and the steel grade 1010 was a commercial low carbon steel. The chemical compositions of all examined steels were determined by optical emission spectroscopy and are summarized in Table 1. Note that the given composition of the Nam-Phee steel was the average value, since the measurement showed quite large fluctuation for different areas. It is seen that the Nam-Phee steel is a low carbon steel and had highly inhomogeneous composition that was likely due to its simple casting process under uncontrolled condition.

Table 1. Determined chemical compositions (wt. \%) of the investigated steels.

\begin{tabular}{cccccc}
\hline Steel type & C & Si & P & S & Mn \\
\hline Nam-Phee & 0.252 & 0.026 & 0.011 & 0.003 & - \\
AISI 1055 & 0.550 & 0.200 & 0.030 & 0.035 & 0.700 \\
AISI 1010 & 0.120 & 0.100 & 0.040 & 0.050 & 0.400 \\
\hline
\end{tabular}

\subsection{Fold Forging Process}

The fold forging process applied in this work was adapted from the Samurai sword making technique [6,22], as depicted in Fig. 1. Firstly, steels specimens with the approximate dimension of $60 \times 350 \times 5 \mathrm{~mm}$ were prepared. The specimens were heated up to the temperature of about $1100^{\circ} \mathrm{C}$ and held for $10 \mathrm{~min}$ in a 
charcoal furnace, as used in the traditional process. Note that the temperature on the samples was measured by a thermocouple. Then, the specimens were forged by a helmet. After the first forging, the specimens were divided into two pieces. Then, they were folded and further forged until it became a single uniform sample piece. Here, for every sample with fold-forging condition total 6 folding steps were carried out. Note that the Samurai sword is typically folded and forged for around 10-15 times. It was presumed that 6 folding steps were sufficient to determine the difference of resulting mechanical properties.
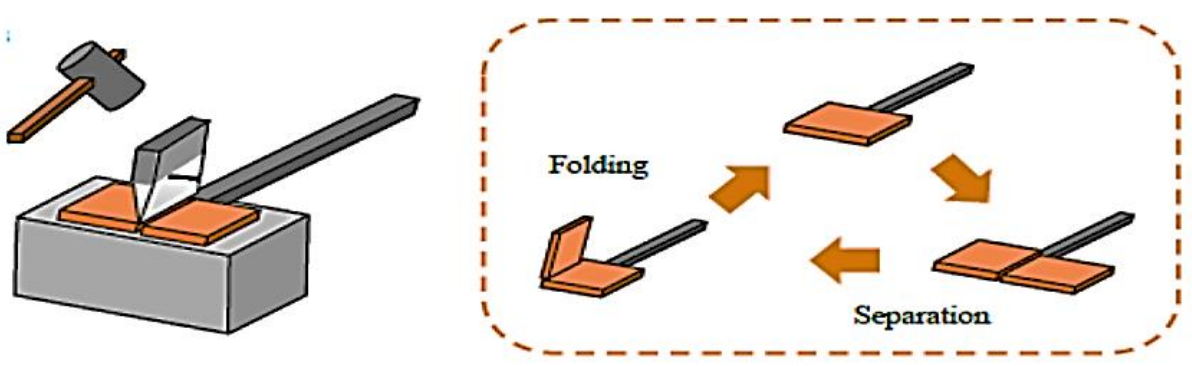

Fig. 1. Schematic of the fold forging process [21].

In this work, three different steel grades including the Nam-Phee steel, medium carbon steel grade 1055 and low carbon steel grade 1010 were taken. For the experiments, a total of four forging conditions were investigated, which were Nam-Phee steel without fold-forging, Nam-Phee steel with fold-forging, 1055 steel grade with fold-forging and 1055 steel grade mixed with the 1010 steel grade including fold-forging, as shown in Table 2. Both simple forging and fold-forging procedures were carried out at the temperature of about $1100^{\circ} \mathrm{C}$. Note that in case of the samples with mixed steels, the outer layer was the high carbon steel grade 1055 and the inner core was the low carbon steel grade 1010. After forging procedure, all samples had the dimension of 140x50x5 mm. In addition, one half the amounts of as-forged samples from all conditions was reheated to the temperature of $900^{\circ} \mathrm{C}$, held for $5 \mathrm{~min}$ and subsequently quenched in water. This quenching was carried out in order to reproduce the actual sword making process and to compare mechanical properties of as-forged with those of as-quenched samples. The applied temperature-time cycle for the experiments is summarized in Fig. 2. Subsequently, metallography examination was carried out for all as-forged and asquenched test samples. Note that test specimens for metallography and mechanical tests were taken from the middle area of the forged samples, in which skin and edge areas were avoided. The phase fractions of each sample were determined by means of an optical image analysis. In addition, Vickers hardness measurement was performed for all specimens.

Table 2. Conditions of steel samples for the investigation.

\begin{tabular}{|c|c|c|c|}
\hline Steel type & Fold-forging & $\begin{array}{c}\text { Without fold- } \\
\text { forging }\end{array}$ & Quenching \\
\hline Nam-Phee & yes & yes & yes \\
\hline AISI 1055 & yes & no & yes \\
\hline AISI 1055 + AISI 1010 & yes & no & yes \\
\hline
\end{tabular}




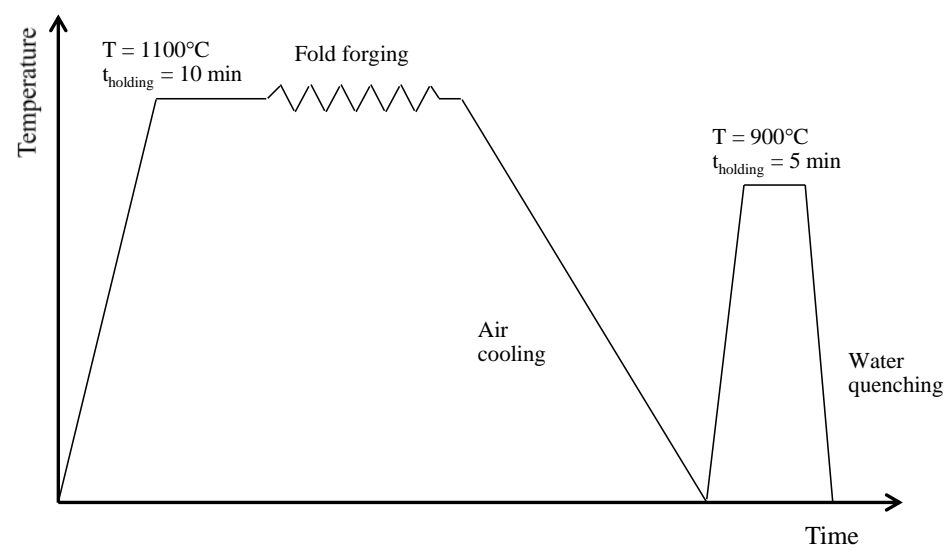

Fig. 2. Temperature-time diagram of the experimental procedure.

\subsection{Microstructure Analysis}

To analyze the microstructure, both as-forged and as-quenched specimens from various forging conditions were prepared by transversely cutting and polishing to obtain a smooth surface. Before the polishing, the specimens were heated to a temperature at $150^{\circ} \mathrm{C}$ for $10 \mathrm{~min}$ to cast with Black Carl Wright and afterwards polished with sandpaper number 240,400,600,800,1000, 1200, 1500 and 2000, respectively. After that, the specimens were fine-polished with a 1-micron alumina powder. To characterize the existing phases in the microstructures, the specimens were etched with $2 \%$ Nital solution for $5 \mathrm{~s}$. Finally, microstructure analyses of the prepared specimens were done by using an optical microscope.

\subsection{Tensile Test}

For tensile tests, steel sheet specimens were prepared from as-quenched test samples according to the standard DIN EN 10002. The tensile tests were conducted at room temperature with the crosshead speed of $3.5 \mathrm{~mm} / \mathrm{min}$, which was equal to the strain rate of $0.00231 / \mathrm{s}$. The dimension of the tensile specimens is shown in Fig. 3. At least five repeated samples were used. Hereby, mechanical properties such as strength and elongation of the specimens from all forging conditions were determined and then compared.



Fig. 3. Dimensions of tensile test specimen.

\subsection{Three-Point Bending Test}

For bending tests, steel sheet specimens were prepared from as-quenched test samples according to the standard ASTM D790. The dimension of the test specimen is shown in Fig. 4. The three point bending test was conducted at room temperature with the crosshead speed of $1.3 \mathrm{~mm} / \mathrm{s}$. All specimens were pressed by a punch until fracture occurred. The bending tests were done for the samples from all forging conditions in order to evaluate bendability and flexural strength of the examined steels. 

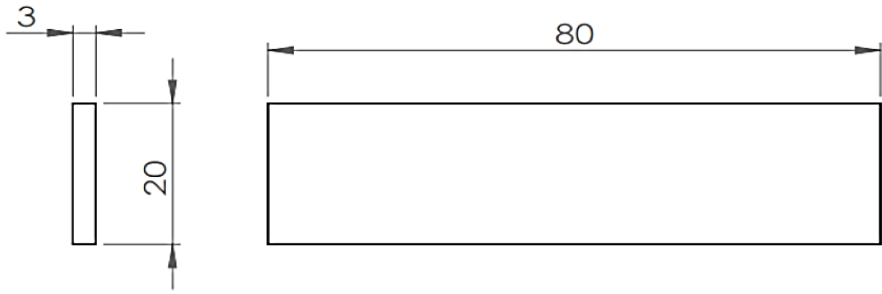

Fig. 4. Dimensions of bending test specimen.

\subsection{Impact Test}

For impact tests, Charpy V-notch steel specimens were prepared from as-quenched test samples according to the standard ASTM E23. The dimension of the test specimens is illustrated in Fig. 5. The impact Charpy tests were performed for the samples from all forging conditions in order to determine and compare achieved energy absorbed of each steel condition under impact load.
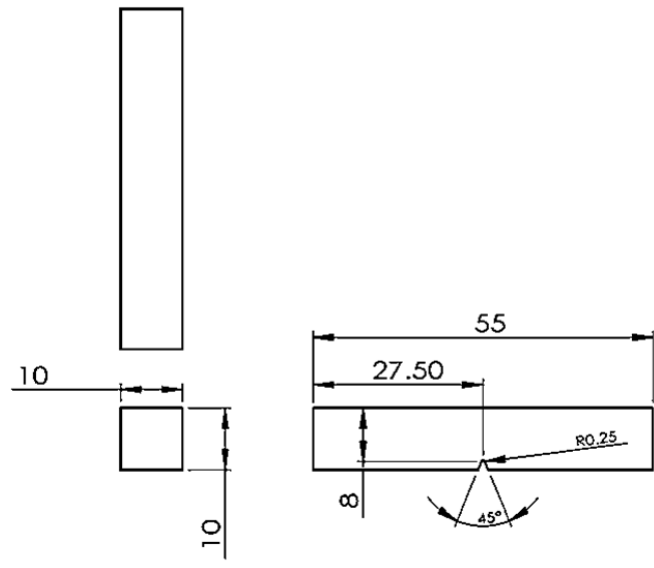

Fig. 5. Dimensions of Charpy V-notch specimen.

\section{Results and Discussion}

\subsection{Microstructure observation}

Figure 6(a) shows the microstructure of as-forged Nam-Phee sample without fold-forging process. It is found that the microstructure consisted of ferritic phase observed along grain boundaries and pearlitic phase appeared as a typical lamella structure. Note that all samples after either fold-forging process or simple forging were cooled down in still air to room temperature before subjecting to quenching. Under this condition, the Nam-Phee steel exhibited about $26 \%$ and $74 \%$ ferritic and pearlitic phase fraction, respectively. Figure $7(a)$ depicts the microstructure of as-forged Nam-Phee sample undergoing the fold-forging process. It is seen that this microstructure contained lower amount of pearlite, since decarburizing likely occurred during the heating of some samples. However, the fold-forging could significantly lead to much finer microstructure and likely more homogeneous carbon distribution. Figure 8(a) illustrates the microstructure of as-forged sample of steel grade 1055 mixed with steel grade 1010 subjected to the fold-forging. This microstructure was taken from the area of the high carbon steel. It can be observed that the microstructure contained higher amount of pearlite and small fractions of ferrite along grain boundaries. The carbon content of the steel grade 1055 was higher than that of the Nam-Phee steel so that higher amount of pearlite was present. Figure 9 (a) shows the microstructure at the border between the high and low carbon steel areas of as-forged samples with mixed steel grades including the fold-forging. It is obvious that both steels were separated into two regions by a thin layer. The microstructure on the side of the high carbon steel grade was similar to that in Fig. 8(a). The microstructure on the side of the low carbon steel contained about $51 \%$ ferritic phase and $49 \%$ pearlitic phase, which was similar to that of the Nam-Phee steel with fold-forging, but somewhat larger and more elongated 
structure. Figures 6(b), 7(b), 8(b) and 9(b) depict the as-quenched microstructures of samples with different steels and forging conditions corresponding to the shown as-forged microstructures. It is seen that almost fully martensitic structures with different package and lath sizes took place along with small amount of ferrite. The fold-forging process led to finer martensitic structure in as-quenched samples.

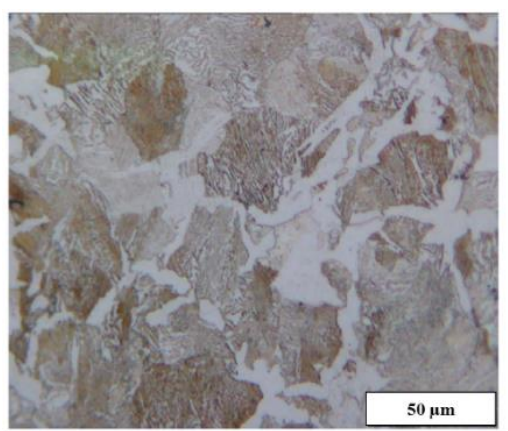

(a)

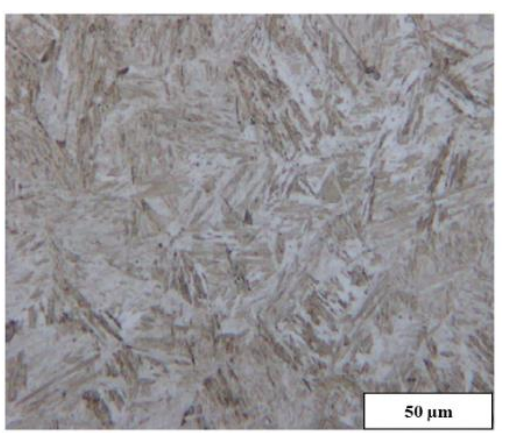

(b)

Fig. 6. Observed microstructures of Nam-Phee steel sample without fold-forging process: (a) as-forged and (b) as-quenched.

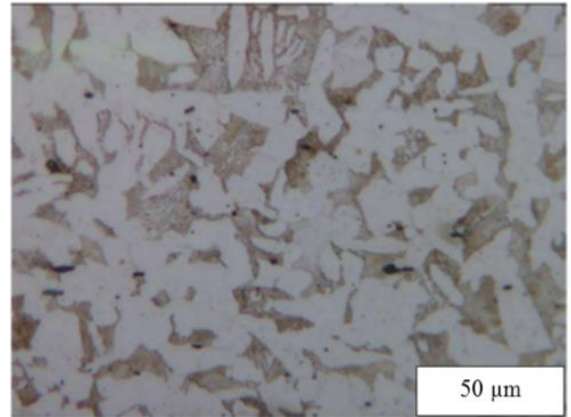

(a)

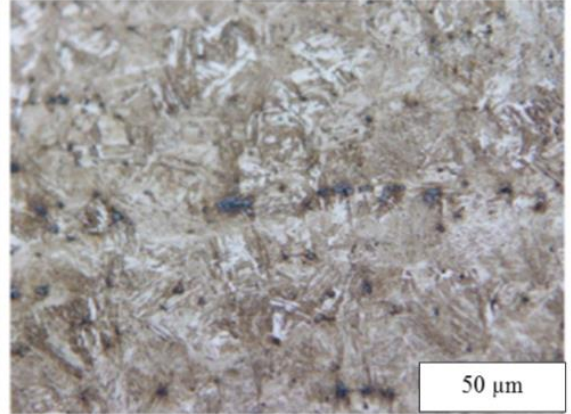

(b)

Fig. 7. Observed microstructures of Nam-Phee steel sample with fold-forging process: (a) as-forged and (b) as-quenched.

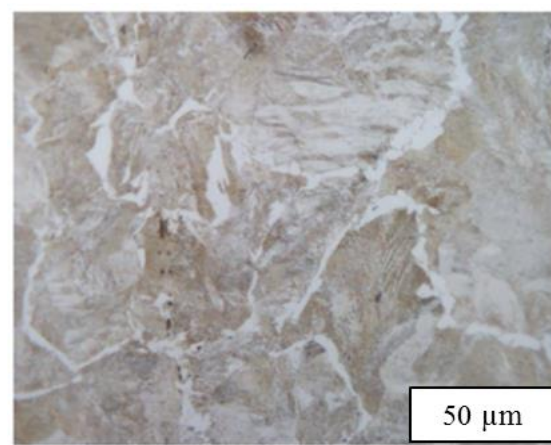

(a)

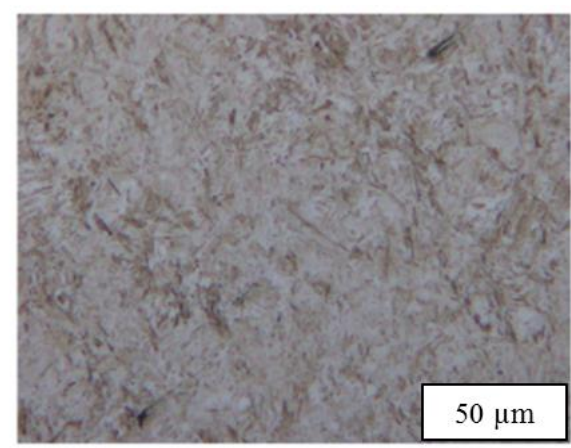

(b)

Fig. 8. Observed microstructure within the area of the high carbon steel of sample with mixed steel grades undergoing fold-forging process: (a) as-forged and (b) as-quenched. 


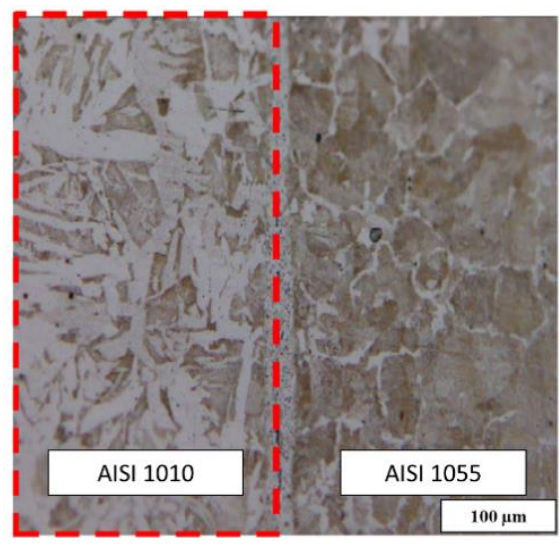

(a)

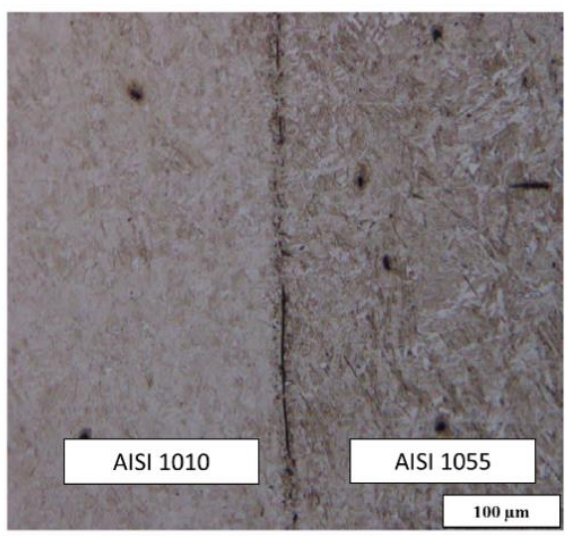

(b)

Fig. 9. Observed microstructure at the border between two steels of sample with mixed steel grades undergoing fold-forging process: (a) as-forged and (b) as-quenched.

Figures 10 and 11 provide the results of phase analysis for the as-forged and as-quenched samples in comparison, respectively. Before quenching, the as-forged samples exhibited ferrite-pearlite structure with different phase fractions according to the carbon content of the steels. The amount of ferrite in the NamPhee samples with fold-forging increased due to the decarburizing according to the observed optical micrographs. No fully martensitic microstructure was obtained in any as-quenched samples. However, significantly higher amount of martensite was found in 1055 steel samples than in other samples. The martensitic phase fraction in Nam-Phee steel samples was higher than that in low carbon steel samples. It is also seen that the martensite contents in the as-quenched Nam-Phee steel samples with and without foldforging were similar, but the as-quenched samples with fold-forging showed finer lath and package sizes.

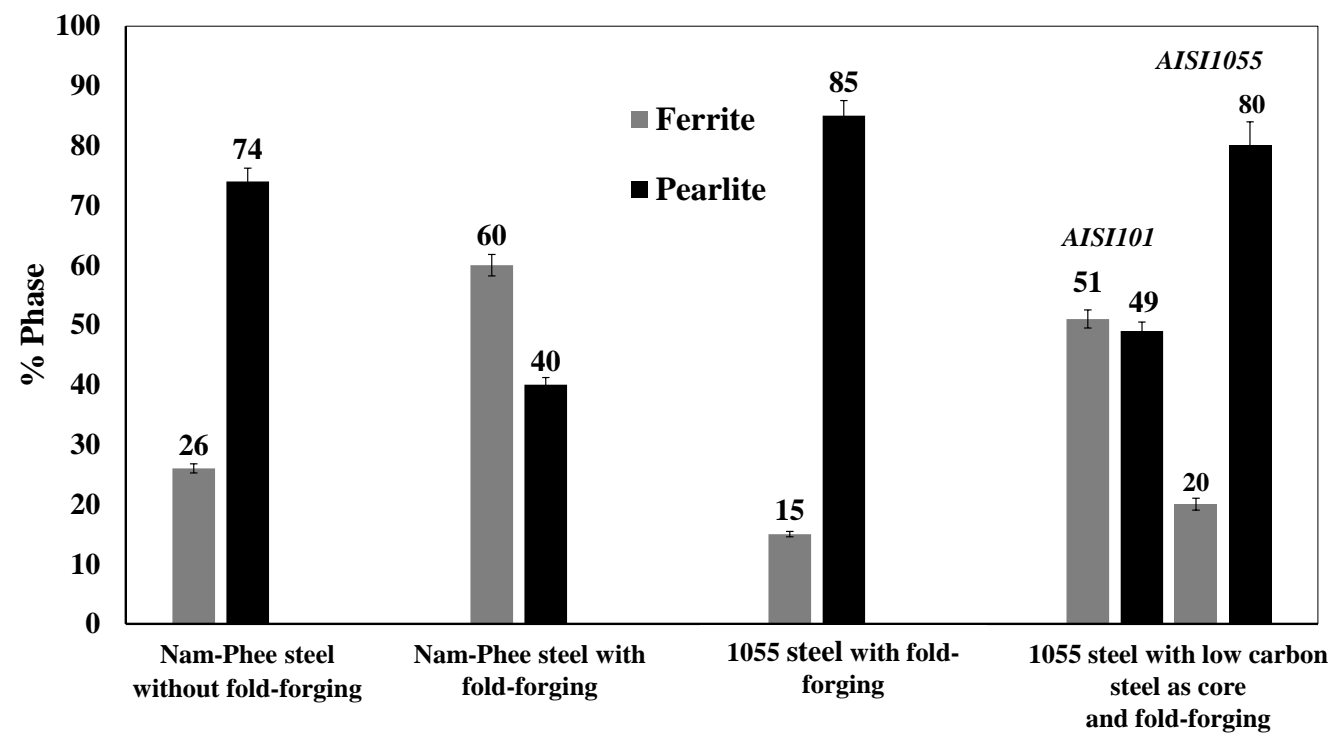

Fig. 10. Measured phase fractions of as-forged samples with various testing conditions. 


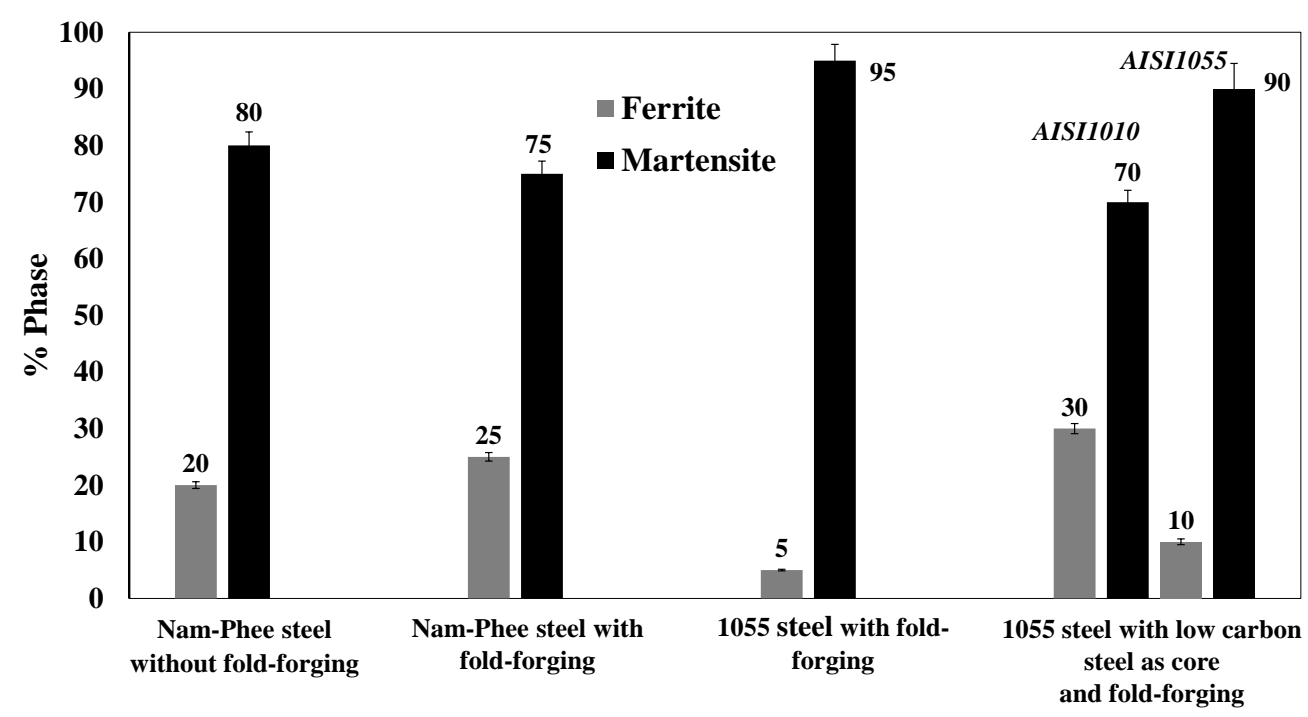

Fig. 11. Measured phase fractions of as-quenched samples with various testing conditions.

\subsection{Hardness Test}

Macro hardness tests in the Rockwell scale C (HRC) were performed for all samples using an indent force of $99.96 \mathrm{~kg}$. Figure 12 shows the hardness comparisons for the examined as-forged and as-quenched samples. The hardness of 1055 steel samples was highest because of the largest carbon content in comparison to other steels. Before quenching, as-forged Nam-Phee steel samples with and without fold-forging exhibited the lowest hardness values, but the as-quenched hardnesses were significantly increased. The Nam-Phee steel samples with and without fold-forging in both as-forged and as-quenched conditions showed approximately similar hardness values. In general, it was found that the determined hardness values were well correlated with the phase fractions of the investigated steels. Higher amounts of pearlite and martensite basically led to increased hardnesses of as-forged and as-quenched samples, respectively. In spite of the finer martensitic structure of as-quenched Nam-Phee steel samples due to the fold-forging, but no noticeable effect on the hardness value was shown. Nevertheless, it was seen that local hardness values of the Nam-Phee steel samples with fold-forging became more uniform. The high hardness of the 1055 steel samples was caused by larger amount of the martensitic phase. Thus, this steel grade is suitable to be used for the sharp edge area of sword. The area of low carbon steel in as-quenched samples with mixed steel grades exhibited the lowest hardness value, which would enhance ductility of the whole as-quenched sample when using as core.

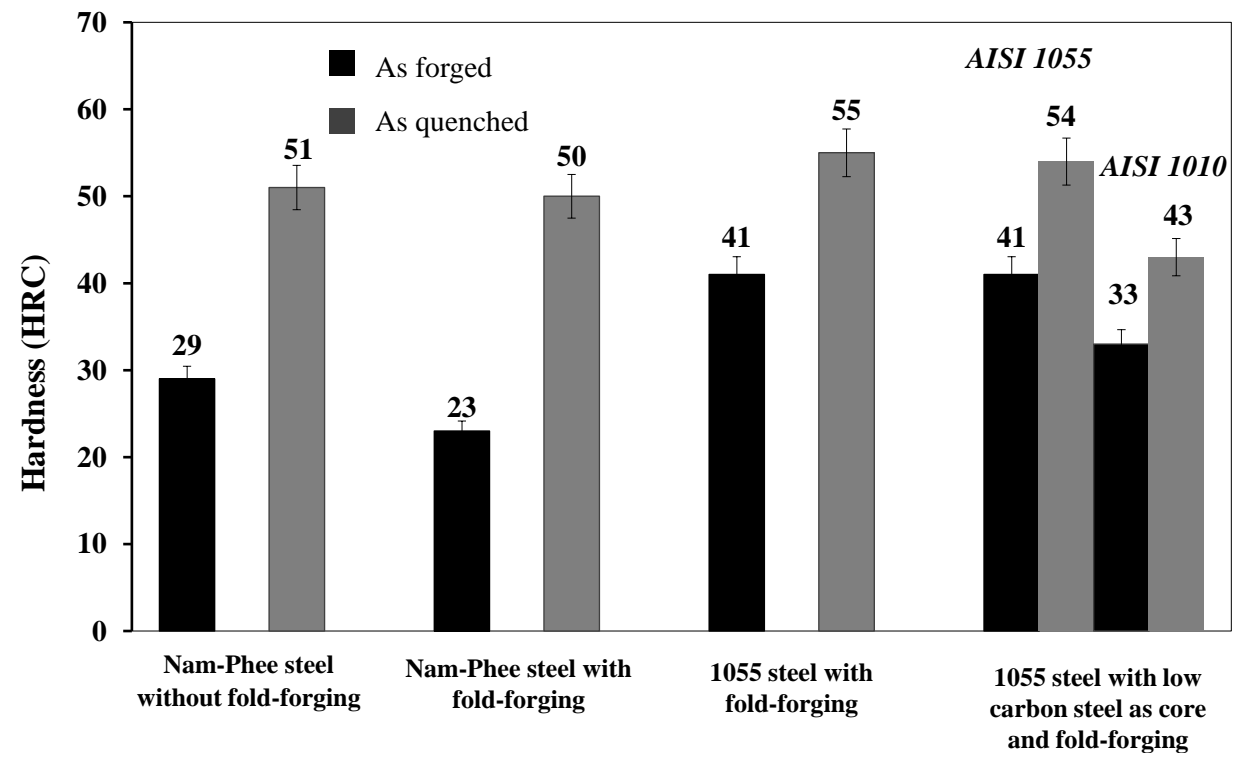


Fig. 12. Measured hardness values of as-forged and as-quenched samples of different steels and forging conditions in comparison.

\subsection{Tensile Test}

The determined engineering stress-strain curves of the as-quenched steel samples are depicted in Fig. 13. Furthermore, tensile properties of the examined samples from all testing conditions including those of the as-quenched Tamahagane steel [8], which was used as sword edge, are presented in comparison in Table 3. These properties were averaged from at least three repeated samples. Note that the as-quenched 1055 steel samples were so hard that slipping occurred during tensile test and fracture took place outside of the gauge length. Thus, its stress-strain curve was not included in Fig. 13. However, its maximum tensile stress was calculated from the measured hardness value by means of a common empirical formula for the purpose of comparison. It is seen that Nam-Phee samples without fold-forging exhibited not only lower strength but also lower elongation than Nam-Phee samples with fold-forging. This was likely due to the more homogeneous and fine grained microstructure of the samples subjected to fold-forging. The 1055 steel samples with fold-forging showed the largest achieved tensile stress according to the obtained hardness value and martensitic phase fraction. The samples of 1055 steel mixed with 1010 steel including fold-forging exhibited the highest ductility. It is observed that these samples reached the maximum stress when fracture occurred in the region of the more brittle high carbon steel. Nevertheless, the samples could be still further elongated because of the ductile core of the low carbon steel. The maximum achieved tensile stress of the Nam-Phee steel samples with fold-forging was comparable to the tensile strength of the Tamahagane steel [8].

Additionally, fracture surfaces of all as-quenched tensile specimens were analyzed by scanning electron microscope (SEM). Obviously, the Nam-Phee samples without fold-forging completely failed in a brittle manner, as seen in Fig. 14(a). They exhibited large cleavage fracture planes because of present coarse martensitic structure. In contrast, the Nam-Phee samples with fold-forging showed much finer fracture planes. From the results of the as-quenched samples of mixed steel grades with fold-forging, it was found that the belonging 1055 steel region also showed a brittle fracture character, as in Fig. 15(a) and Fig. 15(b). Figure 15(c) illustrates different fracture surfaces of low carbon steel region of the same samples, in which dimple fracture was apparently visible along with cleavage fracture. The presented fracture characteristics can be well correlated with the results of the tensile tests.

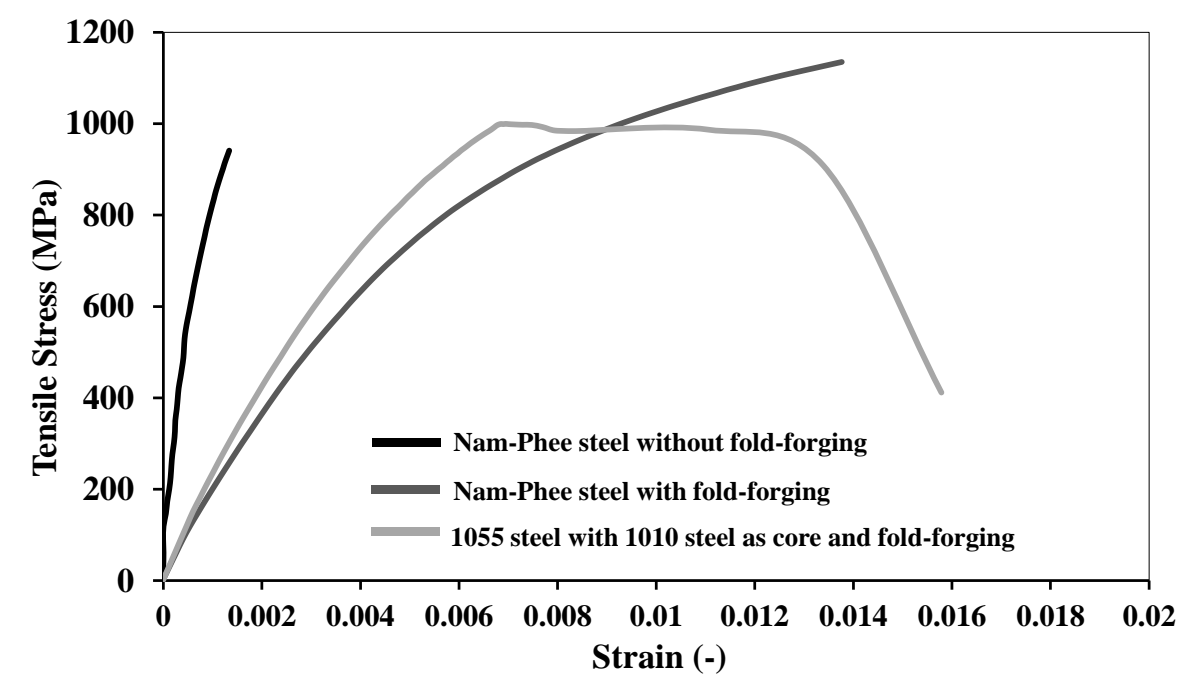

Fig. 13. Determined engineering stress-strain curves of as-quenched samples from all testing conditions.

Table 3. Tensile properties of as-quenched samples from all testing conditions. 


\begin{tabular}{|c|c|c|}
\hline Steel type & $\begin{array}{c}\text { Max. tensile stress } \\
{[\mathrm{MPa}]}\end{array}$ & $\begin{array}{c}\text { Max. Elongation } \\
{[\%]}\end{array}$ \\
\hline Nam-Phee without fold-forging & 931 & 0.1 \\
\hline Nam-Phee with fold-forging & 1130 & 1.3 \\
\hline AISI 1055 with fold-forging & $1379 *$ & n.a \\
\hline AISI 1055 with AISI 1010 and fold-forging & 999 & 1.5 \\
\hline Tamahagane steel (as sword edge) [8] & 1160 & n.a \\
\hline
\end{tabular}

*Calculated using hardness values

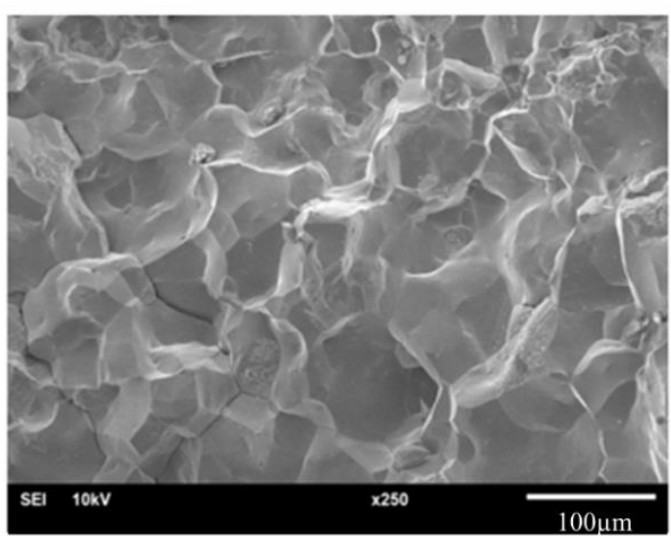

(a)

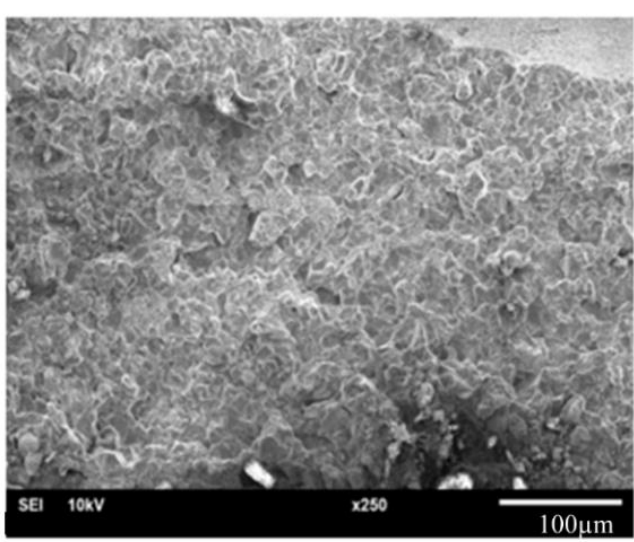

(b)

Fig. 14. Fracture surfaces of (a) as quenched Nam-Phee tensile sample without fold-forging and (b) asquenched Nam-Phee tensile sample with fold-forging.

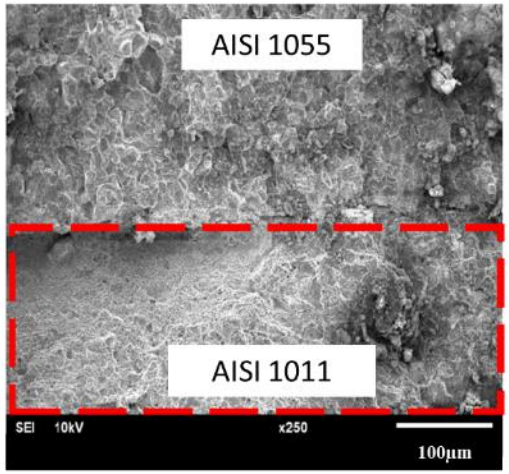

(a)

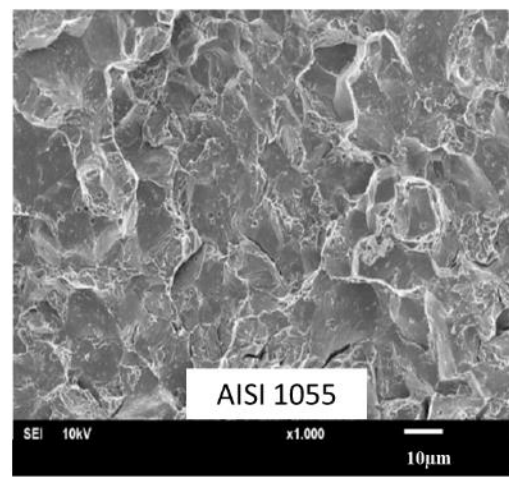

(b)

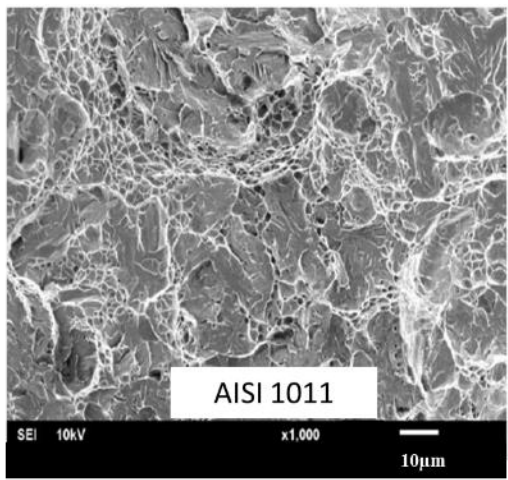

(c)

Fig. 15. Fracture surfaces of as-quenched samples of mixed steel grades with fold-forging: at (a) the border between both steels, (b) high carbon steel region and (c) low carbon steel region.

\subsection{Bending Test}

The results of three-point bending tests are shown as flexural stress and strain curves for as-quenched samples from all testing conditions in Fig. 16. Furthermore, their maximum flexural stresses and flexural moduli were determined and provided for comparison in Fig. 17. Note that these values were averaged from at least three repeated samples. The maximum flexural stress and strain of as-quenched Nam-Phee steel samples without fold-forging were quite low, because microstructure of these samples was inhomogeneous and some large 
inclusions were also present. The as-quenched 1055 steel samples with fold-forging showed flexural stress similar to that of the Nam-Phee samples without fold-forging, while their flexural strain was somewhat lower, as seen in Fig. 16. Applying the fold-forging caused as-quenched Nam-Phee steel samples to have larger flexural stress and significantly increased flexural strain. The highest flexural stress was achieved in the case of as-quenched samples of mixed steel grades including fold-forging. This was due to the combined effect of high strength of the high carbon steel and high ductility of the low carbon steel in the sample core. The results from the bending tests were well correlated with those from the tensile tests. It can be noticed that the bendability of Nam-Phee steel could be increased by the fold forging process. In addition, mixing with more ductile steel grade also considerably provided enhanced bendability of sword. Generally, the high carbon steel exhibited slightly higher flexural modulus values than the Nam-Phee steel. It meant higher stiffness against bending stress.

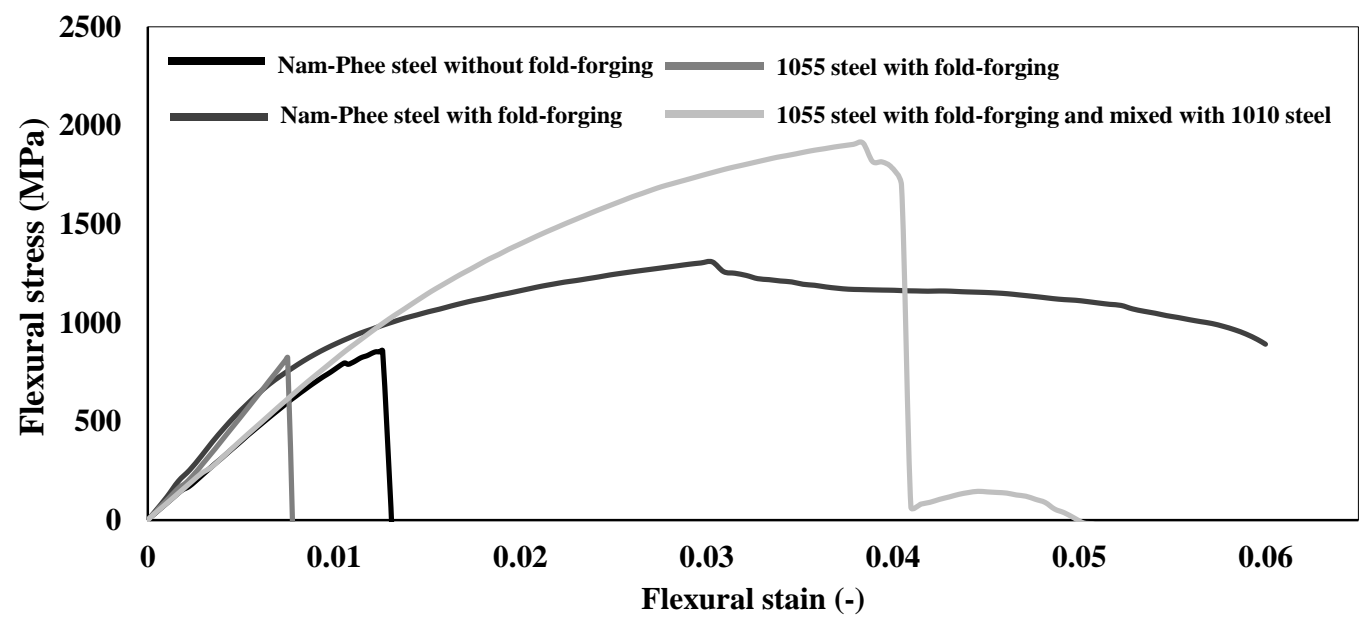

Fig. 16. Determined flexural stress and strain curves of as-quenched samples from all testing conditions.

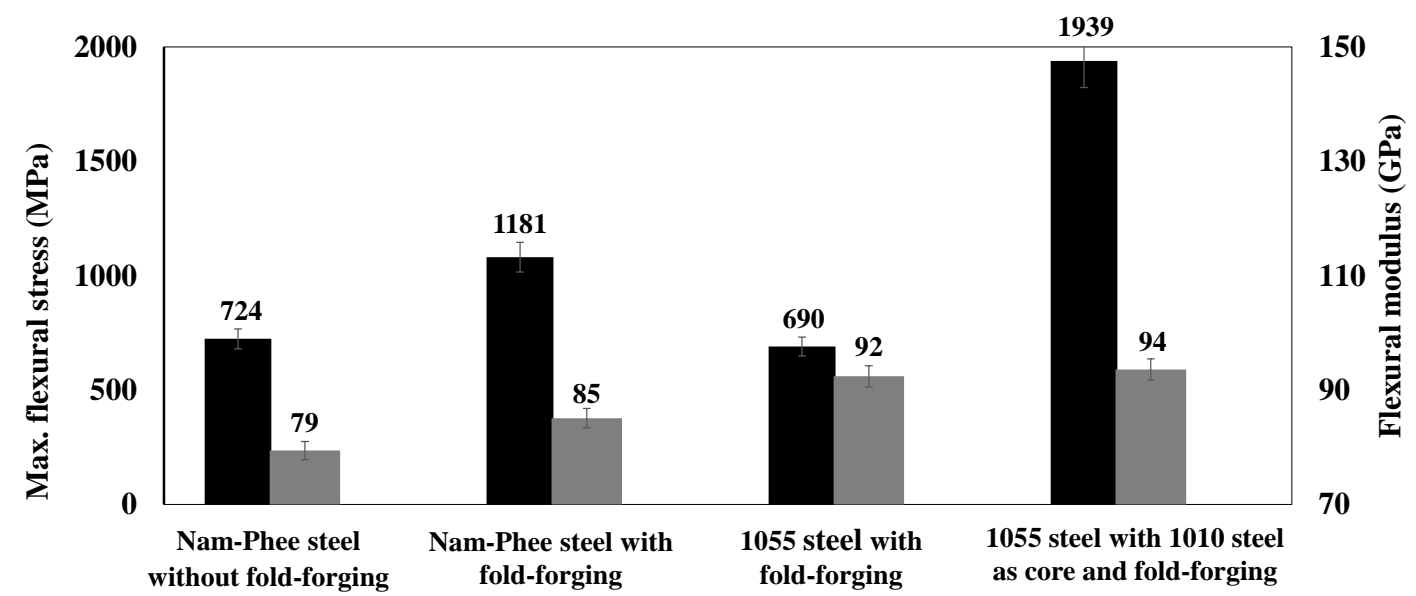

Fig. 17. Determined maximum flexural stress and flexural modulus of the as-quenched samples from all testing conditions.

\subsection{Impact Test}

Fig. 18 presents the impact energy values determined by the Charpy tests of all as-quenched steel samples. It was found that as-quenched Nam-Phee steel samples without fold-forging and as-quenched 1055 steel samples with fold-forging showed noticeably lower impact energies. These results fairly agreed with observed SEM images, in which fracture of the samples occurred in a relative brittle manner as continuous and planar fracture surfaces. Nevertheless, the as-quenched Nam-Phee steel with fold-forging exhibited significantly 
increased impact energy, which even approximately achieved the impact energy of the samples of mixed steel grades. The fold-forging process and steel mixing method enhanced the fracture resistance of steel samples. The results were in accordance with those from the tensile and bending tests.

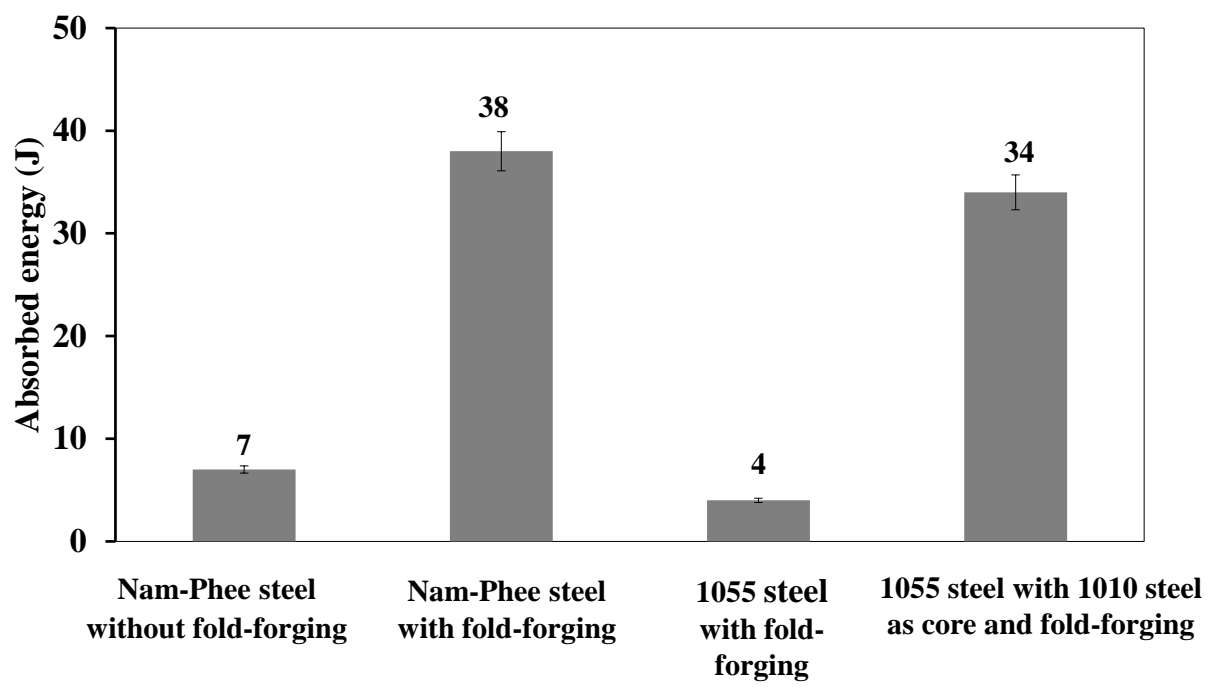

Fig. 18. Impact energies determined by Charpy test of as-quenched samples from all testing conditions.

\section{Conclusions}

According to the results, the following conclusions can be drawn.

- The fold-forging process led to Nam-Phee steel with more homogeneous and finer microstructure.

- The fold-forging process could enhance tensile stress, flexural stress, flexural strain and impact energy of the Nam-Phee steel.

- The steel mixing method with more ductile steel as core and high strength steel as case improved both bendability and impact energy.

- Tensile strength of the Tamahagane steel for Samurai sword could be achieved by applying the fold-forging process to the Nam-Phee steel.

\section{References}

[1] W. Suwatchai and P. Adul, "A comparison of the engineering properties of Nam Phi steel," Indus. Tech. Lampang Rajabhat Univ. J., vol. 1, pp. 92-105, 2015.

[2] C. Matsumoto, A. K. Das, T. Ohba, S. Morito, T. Hayashi, and G. Takami, "Characteristics of Japanese sword produced from tatara steel,” J. Alloys Compounds, vol. 577, suppl. 1, pp. 673-677, Nov. 2013.

[3] T. Inoue, "Tatara and the Japanese sword: The science and technology," Acta Mech., vol. 214, no. 1, pp. 17-30, Oct. 2010.

[4] T. Inoue, "Science of Tatara and Japanese sword-traditional technology viewed from modern science," in the 1st International Conference on Business and Technology Transfer, Kyoto, Japan, 2002, pp. 131-138.

[5] A. K. Das, T. Ohba, S. Morito, G. Takami, T. Fujikawa, and M. Yaso, "Characteristic feature found in typical TATARA product, Japanese sword," in 8th European Symposium on Martensitic Transformations, Prague, Czech Republic, 2009, doi:10.1051/esomat/200902024.

[6] G. Takami, T. Ohba, S. Morito, and A. K. Das, "Microstructure observation on material of the Japanese sword under fold-forging process," Mater. Sci. Forum, vol. 654-656, pp. 134-137, June, 2010.

[7] J. Wadsworth, "Archeometallurgy related to swords," Mater. Charac., vol. 99, pp. 1-7, Jan. 2015.

[8] W. Kochmann, M. Reibold, R. Goldberg, W. Hauffe, A. A. Levin, D. C. Meyer, T. Stephan, H. Müller, A. Belger, and P. Paufler, "Nanowires in ancient Damascus steel," J. Alloys Compounds, vol. 372, no. 1-2, pp. L15-L19, June, 2004. 
[9] M. R. Notis, "The history of the metallographic study of the Japanese sword," Mater. Charac., vol. 45, no. 4-5, pp.253-258, Oct.-Nov. 2000.

[10] O. D. Sherby and J. Wadsworth, "Ancient blacksmiths, the Iron Age, Damascus steel and modern metallurgy," J. Mater. Proc. Tech., vol. 117, no. 3, pp. 347-353, Nov. 2001.

[11] H. J. S. Withers, The Pictorial History of The Sword. London, United Kingdom: Anness Publishing, 2010.

[12] R. E. Oakeshott, The Archaeology of Weapons Arms and Armour from Prehistory to the Age of Chivaly. NY: Dover Publications, 1996.

[13] R. F. Burton, The Book of the Sword, revised ed. NY: Dover Publications, 1987.

[14] R. E. Oakeshott, A Knight and His Weapons, revised ed. PA: Dufour Editions, 1997.

[15] S. Nagashima, Y. Shiota, H. Sato, T. Kamiyama, M. Ohnuma, and Y. Kiyanagi, "Imaging of crystalline structural information of Japanese swords by pulsed neutron transmission spectroscopy," Physics Procedia, vol. 60, pp. 327-331, Dec. 2014.

[16] K. Kino, N. Ayukawa, Y. Kiyanagi, T. Uchida, S. Uno, F. Grazzi, and A. Scherillo, "Analysis of crystallographic structure of a Japanese sword by the pulsed neutron transmission method," Physics Procedia, vol. 43, pp. 360-364, April, 2013.

[17] M. Yaso, T. Takaiwa, Y. Minagi, K. Kubota, S. Morito, T. Ohba, and A. K. Das, "Study of microstructures on cross section of Japanese sword," in 8th European Symposium on Martensitic Transformations, Prague, Czech Republic, 2009, doi:10.1051/esomat/200902024.

[18] M. Yaso, T. Takaiwa, Y. Minagi, T. Kanaizumi, K. Kubota, T. Hayashi, S. Morito, and T. Ohba, "Study of Japanese sword from a viewpoint of steel strength," J. Alloys Compounds, vol. 577, suppl. 1, pp. S690S694, Nov. 2013.

[19] T. Khoukit and C. Tangthieng, "A numerical investigation of the temperature uniformity of a billet due to thermal radiation in a reheating furnace," Engineering Journal, vol. 20, no. 1, pp. 35-46, Jan. 2016.

[20] H. S. Zhang, "Technology study of the roll-forging forming of swords," J. Mater. Proc. Tech., vol. 63, no. 1-3, pp. 265-268, Jan. 1997.

[21] M. Morimoto, "The forging of a Japanese Katana," Colorado School of Mines, Colorado, June, 2004.

[22] M. Okayasu, H. Sakai, and T. Tanaka, "Mechanical properties of Samurai swords (carbon steel) made using a traditional steelmaking technology (tatara)," J. Mater. Sci. Eng., vol. 4, no. 2, pp. 1-6, Apr. 2015. doi: 10.4172/2169-0022.1000162 